\title{
An Empirical Examination of Investment Risk Management Models for Serbia, Hungary, Croatia and Slovenia
}

\author{
Vladimir Djakovic
}

University of Novi Sad, Faculty of Technical Sciences, Trg Dositeja Obradovica 6, 21000 Novi Sad, Serbia, v_djakovic@uns.ac.rs

\section{Igor Mladenovic}

University of Nis, Faculty of Economics, Trg Kralja Aleksandra 11, 18000 Nis, Serbia, igor.mladenovic@eknfak.ni.ac.rs

\section{Goran Andjelic}

Educons University, Faculty of Business Economy, Vojvode Putnika 87, 21208 Sremska Kamenica, Serbia, goran.andjelic@educons.edu.rs

\footnotetext{
Abstract: The research presented in the study is the analysis and implementation of parametric and non-parametric Value at Risk (VaR) calculation models for predicting risk and determining the maximum potential loss from investment activities. The study sample includes stock indices of Serbian (BELEX15), Hungarian (BUX), Croatian (CROBEX) and Slovenian (SBITOP) markets, from $1^{\text {st }}$ January 2006 to $31^{\text {st }}$ December 2012. The methodology connotes the use of analysis and synthesis, as well as relevant statistical and mathematical methods. The study is based on the assumption that there is no statistically significant difference among the different models of risk management, in relation to the performance of investment risk prediction in the markets of the observed transition economies. The main aim of the study is to assess the performances of risk management models in practice, in order to operationally optimize investment decisions. The research results indicate the implementation adequacy of the tested models in the observed transitional markets, with full consideration of their specifics.
}

Keywords: risk management; value at risk; extreme value theory; historical simulation; delta normal VaR 


\section{Introduction}

Contemporary business conditions, characterized by dynamic changes both at micro and macro levels and frequent crises, challenge investing activities with constantly new and increasing risks. In order to successfully overcome the investment risk, in practice, numerous different models of risk management are developed to answer the challenges of ever changing markets and encounter the holders of investment decisions. This study analyzes and tests the implementation of various parametric and non-parametric Value at Risk (VaR) calculation models in order to predict the risk, focusing on the specific transitional markets, namely: Serbia, Hungary, Croatia and Slovenia. The lack of adequate data about the implementation of the chosen empirical models in transitional markets is particularly challenging. Such markets are interesting for the study especially because of their transitional features, and this fact takes on a whole new dimension with the beginning of the global economic crisis.

In accordance with the above mentioned, this study analyzes and tests the implementation of the following models: Extreme Value Theory EVT), Historical Simulations (HS VaR) and Delta Normal VaR (D VaR), with the confidence level of $97.5 \%$ for 100 and 300 days (rolling windows), in the period from 2006 to 2012, for the observed markets. The real origin of the study objective is the researchers' ambition to affect significantly the risk level included in the investing activities by testing the models in observed transitional markets. Thus, the process of investing in these markets will be more acceptable to potential investors, their propulsive and liquidity will be increased, and real preconditions created for their further development and stabilization. In this context, the main objective of the study is to determine the performances of risk management models in practice to optimize investment decisions. The additional targets are set as follows: Ascertain whether the applied risk management models properly evaluate and predict the distribution tails of index daily returns in the target markets; Determine risks and analyze environmental factors important for successful investing; Analyze the implementation possibilities of the selected models in turbulent business conditions, and establish the fundaments and guidelines for further development of the models in practice.

The basic hypothesis $\left(\mathrm{H}_{0}\right)$ is that there is no statistically significant difference among the different models of risk management in relation to the performance of investment risk prediction in transition economy markets.

The derived hypotheses are the following:

$\mathrm{H}_{1}$ : There is no statistically significant difference of the risk management models' effectiveness in risk prediction for the indices in the period 20072012 . 
$\mathrm{H}_{2}$ : There is no clearly defined boundary among the risk management models, in relation to the performance of risk prediction for the indices in the period 2007-2012.

$\mathrm{H}_{3}$ : There is no statistically significant difference of the risk management models' effectiveness in risk prediction for the indices in particular years.

The research results are derived from the author's doctoral thesis [11] and will be useful both to academic and investment communities (public and regulatory). In fact, the results of the research should define the challenges and implementation opportunities of the selected investment risk management models, consistent with current trends in this area. In this way, the relevant guidance and possibilities will be provided to actively monitor the performance of the given risk management models' implementation in the observed transitional markets (Serbia, Hungary, Croatia and Slovenia), to optimize the investment process.

\section{Theoretical Background}

Numerous studies in the field of risk management have been conducted in developed markets, with special focus on the investment process and optimization of investment decisions. There are also studies in this area that indicate the specifics of transitional markets in the context of adequate risk prediction. This study is determined to analyze and test the performance of the risk management models' implementation in transitional markets because of their similar characteristics, i.e. the significant level of similarity in the markets of Serbia, Hungary, Croatia and Slovenia [1].

Basak and Shapiro [8] analyze the factors that affect the design of optimal, dynamic portfolio, with special emphasis on the market risk management using the Value at Risk models. In this context, they specifically investigate the impact of risky assets on the extreme portfolio losses. In order to invest efficiently, the authors propose an alternative model of risk management (LEL-RM) in order to eliminate $\mathrm{VaR}$ deficiencies, i.e. reduce the potential loss from investing activities. The authors particularly emphasize the necessity of incorporating the stock market volatility in the concerned model and the importance of permanent credit risk, which affects the expected return from the investment process.

Ait-Sahalia and Lo [12] suggest the implementation of nonparametric Value at Risk model of risk management to evaluate adequately extreme losses in investments. The authors imply how important it is to adjust the given model to risk aversion, investment time horizon and other important factors that influence the assessment and validation of investment risk. They also conclude that the statistical risk measures do not fully reflect the level of portfolio uncertainty, and that definition of maximum potential loss involves the analysis of environmental 
conditions and economic validation of investment activities. Consequently, the authors present an alternative to statistical VaR and Arrow-Debreu framework in evaluating the economic VaR.

Rosenberg and Schuermann [4] indicate the importance of integrated risk management as a basis for measuring and managing risk and capital, with particular emphasis on the market and investment credit risk. They analyze measures of skewness and kurtosis and the thickness of the tails, i.e. the investment return distribution. This research is significant because it indicates the correlation between business risk and total investment risk, and correlative links between different types of risk. The above mentioned points to the complexity of investment risk prediction using a Value at Risk model. Consequently, the authors suggest a hybrid approach to enable adequate risk predictions, and particularly emphasize the importance of information, correlations, and unique risk characteristics.

Zikovic and Pecaric [9] analyze the implementation of Value at Risk investment model in distinctly transitional Croatian market. The focus of the research is the index of the Zagreb Stock Exchange (CROBEX). The research is particularly important because it points to the starting points and guidelines in the application of $\mathrm{VaR}$ models in transitional markets, especially in time of global economic crisis. The testing results of the implementation of VaR models indicate the discrepancy between actual and expected levels of risk resulting from extreme events in the market or extreme movements in stock returns. The authors conclude that the risk management models based on Extreme Value Theory (generalized Pareto distribution) have better performance in the prediction of risk/return of CROBEX stock index.

Campbell et al. [7] develop a portfolio selection model which is focused on maximizing the return from invested assets. In addition, the authors apply the Value at Risk model, i.e. the limits that are established by risk managers in determining the maximum potential loss from investing activities. The research sample consists of risky assets (U.S. stocks and bonds). The authors conclude that there are some similarities when it is assumed that investment returns are normally distributed compared with the mean-variance approach. They also highlight the significance of the impact of alternative time horizons and specific risks in the adequate portfolio selection, i.e. appropriate risk management in investments.

Bucevska [10] analyzes the importance of an adequate risk measure in the business environment which is characterized by negative consequences of global economic crisis. The author tests the Value at Risk performance models on the MBI10 stock exchange index in order to measure transitory market volatility, i.e. risk prediction, in the investment in market of the Republic of Macedonia. The research results of the GARCH model in turbulent business conditions point to the implications of econometric estimate of the given VaR models and show that EGARCH provides the best VaR estimation in the tested transitional market. 
Uppal and Mangla [5] test the extreme losses, i.e. risks because of financial turbulence as a result of global financial crisis. The authors include ten countries in the research, in the period before and during the crisis. Investment risk prediction involves the analysis of the stock returns in the countries. The performances of the Extreme Value Theory model indicate different parameters of the estimated return distribution in the context of adequate investment risk prediction. Uncertainty is a fundamental problem in the implementation of the tested risk management model, especially in the period of frequent extreme events in the monitored markets. The research is important because it identifies key problems of creating extreme risks in investments, i.e. the maximum potential loss from investing activities.

The aforementioned studies provide valuable information for the investment risk prediction, both in developed and transitional markets, particularly in the context of optimal allocation of capital. The actuality of the studies is particularly evident because of existing and new challenges consequent of turbulent business conditions and global economic crisis. The lack of adequate empirical results from this area in transitional markets confirms the necessity of continuous tests of implementation performance of different risk management models, with the special emphasis on prediction of maximum potential loss from investing activities.

\section{Methodology}

The research methodology in the study involves the use of appropriate statistical and mathematical methods to analyze and test performances of different models of investment risk management, i.e. parametric and non-parametric models. Testing of implementation performances of Extreme Value Theory (EVT), Historical Simulation (HS VaR) and Delta Normal VaR (D VaR) models, with the confidence level of $97.5 \%$ for 100 and 300 days (rolling windows), is conducted from 2006 to 2012, in the markets of Serbia, Hungary, Croatia and Slovenia. The research focus is on adequate risk prediction or maximum potential risk from investing activities. The rolling windows of 100 and 300 days are used for the robust risk prediction of different models of risk management. The study sample includes values (returns) of BELEX15, BUX, CROBEX and SBITOP stock indices in the observed markets. The year 2006 is the period over which is calculated the initial value of $\mathrm{VaR}$. The investment risk prediction is calculated on a daily basis depending on VaR rolling windows (100 and 300 days), and at the end of one year period, the number of days with unsuccessful prediction is compared with stock indices in the observed markets. The calculation results for a rolling window of 300 days shown in the subsequent tables cover the period from 2008 to 2012, because of the calculation characteristics, i.e. specifics, for a given 
window. The sample characteristics have non-parametric attributes, so they are therefore analyzed with nonparametric procedures by frequency modalities. The multivariate procedures - MANOVA and discriminant analysis, can be applied to the scaled data. By calculating the discrimination coefficient (d. coeff), the features determining the specifics of subsamples (EVT, HS VaR and D VaR) are insulated, together with the features (years) that should be excluded from further processing, i.e. the observed research space is reduced. The applied univariate procedures are the following: Roy's Test, Pearson's Coefficient of Contingency $(\chi)$ and Multiple Correlation Coefficient (R). The purpose of conducting these procedures is to determine the characteristics of each subsample, as the basis of reliable and accurate prediction, with a certain confidence. MANOVA analysis (Multivariate Analysis of Variance) is used to establish whether there is a difference in the effectiveness of the various risk management models per year during the study period (2007-2012), while Roy's test determines the exact feature (year) of the difference (each year is tested separately). MANOVA analysis tests the hypothesis $\mathrm{H}_{1}$, the discriminant analysis tests the hypothesis $\mathrm{H}_{2}$, while Roy's test is used for the hypothesis $\mathrm{H}_{3}$.

Mathematically, the risk management model can be calculated as follows: The $\Delta \mathrm{p}$ is the change in portfolio value in the next $\mathrm{N}$ days. $\mathrm{VaR}$ then corresponds to the loss (100-a) percentile of the $\Delta \mathrm{p}$ distribution. Then:

$$
P(\Delta P<\operatorname{VaR})=1-a
$$

$\mathrm{VaR}$ is the (100-a) percentile of the distribution value and it is generally calculated on a daily basis, with different levels of confidence. Delta normal VaR is calculated as follows:

$$
\operatorname{VaR}_{\alpha}^{\%}=Z_{\alpha} \sigma
$$

where: $\mathrm{Z}_{\alpha}-$ the value of theoretical distribution, $\sigma-$ standard deviation.

$\mathrm{Z}_{\alpha}$ depends on the confidence level of VaR calculation. [6] in [2]

Extreme Value Theory studies the asymptotic properties of random values, in the forms:

$M_{n}=\max \left\{X_{1}, X_{2}, \ldots, X_{n}\right\} ; m_{n}=\min \left\{X_{1}, X_{2}, \ldots, X_{n}\right\}$

when $\mathrm{n} \rightarrow \infty$, whereat $\mathrm{X}_{1}, \mathrm{X}_{2}, \ldots, \mathrm{X}_{\mathrm{n}}$ are random values with given probability distributions. If for the random value $\mathrm{M}_{\mathrm{n}}$ is valid:

$$
P\left\{\frac{M_{n}-b_{n}}{a_{n}} \leq x\right\} \rightarrow G(x), n \rightarrow \infty
$$

where $G(x)$ is the non-degenerate distribution function, and $a_{n}>0$ and $b_{n}(n \in N)$ being real numbers, then it is said that $G(x)$ is determined by the marginal distribution of linearly normalized maxima $M_{n}$, with $a_{n}$ and $b_{n}$ being stipulating constants. [3] 


\section{Preliminary Data Analysis}

Owing to the available historical data and the possibility of an adequate performance analysis of the implementation of Extreme Value Theory (EVT), Historical Simulation (HS VaR) and Delta Normal VaR (D VaR) models for investment risk predicting in the markets of Serbia, Croatia, Slovenia and Hungary, the research sample includes the daily returns of the market indices during the period from $1^{\text {st }}$ January 2006 to $31^{\text {st }}$ December 2012, i.e. a total of 1764 observation days. The year 2006 is used as the initial period for calculating VaR.

Table 1

Kolmogorov-Smirnov test of the normality of the distribution sample in 2006

\begin{tabular}{|l|c|r|r|r|r|}
\hline & & CROBEX & \multicolumn{1}{c|}{ BUX } & \multicolumn{1}{c|}{ SBITOP } & \multicolumn{1}{c|}{ BELEX15 } \\
\hline N & & 252 & 252 & 252 & 252 \\
\hline Normal Parameterg th & Mean & 2714.8106 & 22522.3334 & 1190.7842 & 1246.1715 \\
\hline & $\begin{array}{c}\text { Std. } \\
\text { Deviation }\end{array}$ & 426.87002 & 1274.48005 & 163.50757 & 191.01019 \\
\hline $\begin{array}{l}\text { Most Extreme } \\
\text { Differences }\end{array}$ & Absolute & 0.152 & 0.098 & 0.146 & 0.222 \\
\hline & Positive & 0.120 & 0.058 & 0.146 & 0.222 \\
\hline & Negative & -0.152 & -0.098 & -0.063 & -0.111 \\
\hline Kolmogorov-Smimov Z & & 2.419 & 1.553 & 2.318 & 3.522 \\
\hline Asymp. Sig.(2-tailed) & (p) & 0.000 & 0.016 & 0.000 & 0.000 \\
\hline
\end{tabular}

Tables 1-7: ${ }^{a}$ Test distribution is Normal; ${ }^{b}$ Calculated from data

Source: the author's calculations [11]

Based on the 2006 Kolmogorov-Smirnov test results, it can be concluded that the values of the observed indices are not normally distributed, i.e. there are significant differences between the sampling distribution and the normal distribution, as indicated by the values of (p) for CROBEX (0.000), BUX (0.016), SBITOP (0.000) and BELEX15 (0.000) (Table 1).

Table 2

Kolmogorov-Smirnov test of the normality of the distribution sample in 2007

\begin{tabular}{|l|c|r|r|r|r|}
\hline & & CROBEX & \multicolumn{1}{c|}{ BUX } & \multicolumn{1}{c|}{ SBITOP } & BELEX15 \\
\hline N & & 252 & 252 & 252 & 252 \\
\hline Normal Parameters & Mean & 4583.3379 & 26099.6362 & 2159.6792 & 2615.7545 \\
\hline & $\begin{array}{c}\text { Std. } \\
\text { Deviation }\end{array}$ & 558.84969 & 1881.77510 & 397.25782 & 378.11747 \\
\hline $\begin{array}{l}\text { Most Extreme } \\
\text { Differences }\end{array}$ & Absolute & 0.213 & 0.101 & 0.177 & 0.203 \\
\hline & Positive & 0.094 & 0.101 & 0.138 & 0.106 \\
\hline & Negative & -0.213 & -0.034 & -0.177 & -0.203 \\
\hline Kolmogorov-Smimov Z & & 3.377 & 1.590 & 2.814 & 3.221 \\
\hline Asymp. Sig.(2-tailed) & (p) & 0.000 & 0.012 & 0.000 & 0.000 \\
\hline
\end{tabular}


Based on the 2007 Kolmogorov-Smirnov test results, it can be concluded that the values of the observed indices are not normally distributed, i.e. there are significant differences between the sampling distribution and the normal distribution, as indicated by the values of (p) for CROBEX (0.000), BUX (0.012), SBITOP (0.000) and BELEX15 (0.000) (Table 2).

Table 3

Kolmogorov-Smirnov test of the normality of the distribution sample in 2008

\begin{tabular}{|c|c|c|c|c|c|}
\hline & & CROBEX & BUX & SBITOP & BELEX15 \\
\hline $\mathrm{N}$ & & 252 & 252 & 252 & 252 \\
\hline \multirow[t]{2}{*}{ Normal Parameters 2.6} & Mean & 3414.7449 & 19800.2232 & 1673.6265 & 1436.8290 \\
\hline & $\begin{array}{c}\text { Std. } \\
\text { Deviation }\end{array}$ & 914.35999 & 4141.47022 & 433.49060 & 543.20959 \\
\hline \multirow[t]{3}{*}{$\begin{array}{l}\text { Most Extreme } \\
\text { Differences }\end{array}$} & Absolute & 0.190 & 0.211 & 0.126 & 0.118 \\
\hline & Positive & 0.084 & 0.124 & 0.071 & 0.108 \\
\hline & Negative & $=0.196$ & -0.211 & -0.126 & -0.118 \\
\hline Kolmogorov-Smimov Z & & 3.117 & 3.343 & 2.005 & 1.877 \\
\hline Asymp. Sig-(2-tailed) & (p) & 0.000 & 0.000 & 0.001 & 0.002 \\
\hline
\end{tabular}

Based on the 2008 Kolmogorov-Smirnov test results, it can be concluded that the values of the observed indices are not normally distributed, i.e. there are significant differences between the sampling distribution and the normal distribution, as indicated by the values of (p) for CROBEX (0.000), BUX (0.000), SBITOP (0.001) and BELEX15 (0.002) (Table 3).

Table 4

Kolmogorov-Smirnov test of the normality of the distribution sample in 2009

\begin{tabular}{|c|c|c|c|c|c|}
\hline & & CROBEX & BLX & SBITOP & BELEX15 \\
\hline $\mathrm{N}$ & & 252 & 252 & 252 & 252 \\
\hline \multirow[t]{2}{*}{ Normal Parameters ${ }^{2 b}$} & Mean & 1855.5760 & 16047.3393 & 977.6396 & 597.7590 \\
\hline & $\begin{array}{c}\text { Std. } \\
\text { Deviation }\end{array}$ & 267,78054 & 3876.14243 & 79.86016 & 136.76785 \\
\hline \multirow[t]{3}{*}{$\begin{array}{l}\text { Most Extreme } \\
\text { Differences }\end{array}$} & Absolute & 0.084 & 0.130 & 0.164 & 0.073 \\
\hline & Positive & 0.067 & 0.115 & 0.094 & 0.073 \\
\hline & Negative & -0.084 & -0.130 & -0.164 & -0.057 \\
\hline Kolmogorov-Smimov Z & & 1.328 & 2.057 & 2.604 & 1.160 \\
\hline Asymp, Sig. (2-tailed) & (p) & 0.059 & 0.000 & 0.000 & 0.136 \\
\hline
\end{tabular}

Based on the 2009 Kolmogorov-Smirnov test results, it can be concluded that the values of BUX and SBITOP indices are not normally distributed, i.e. there are significant differences between the sampling distribution and the normal distribution, as indicated by the values of (p) for BUX (0.000) and SBITOP (0.000). The values of CROBEX index are normally distributed, with the increased conclusion risk (0.059). BELEX15 index values are normally distributed (0.136) (Table 4). 
Table 5

Kolmogorov-Smirnov test of the normality of the distribution sample in 2010

\begin{tabular}{|c|c|c|c|c|c|}
\hline & & CROBEX & BUX & SBITOP & BELEX15 \\
\hline $\mathrm{N}$ & & 252 & 252 & 252 & 252 \\
\hline \multirow[t]{2}{*}{ Normal Parameters ${ }^{\text {tb }}$} & Mean & 1990.4215 & 22482.2929 & 888.5902 & 659.3855 \\
\hline & $\begin{array}{c}\text { Std. } \\
\text { Deviation }\end{array}$ & 136.02370 & 1161.77717 & 66.44689 & 39.43656 \\
\hline \multirow[t]{3}{*}{$\begin{array}{l}\text { Most Extreme } \\
\text { Differences }\end{array}$} & Absolute & 0.173 & 0.072 & 0.158 & 0.147 \\
\hline & Positive & 0.173 & 0.072 & 0.158 & 0.147 \\
\hline & Negative & $=0.14 d$ & -0.043 & $=0.110$ & -0.083 \\
\hline Kolmogorov-Smimov Z & & 2.739 & 1.150 & 2.514 & 2.338 \\
\hline Asymp. Sig. (2-tailed) & (p) & 0.000 & 0.142 & 0.000 & 0.000 \\
\hline
\end{tabular}

Based on the 2010 Kolmogorov-Smirnov test results, it can be concluded that the values of CROBEX, SBITOP and BELEX15 indices are not normally distributed, i.e. there are significant differences between the sampling distribution and the normal distribution, as indicated by the values of (p) for CROBEX (0.000), SBITOP (0.000) and BELEX15 (0.000). The values of BUX index are normally distributed (0.142) (Table 5).

Table 6

Kolmogorov-Smirnov test of the normality of the distribution sample in 2011

\begin{tabular}{|c|c|c|c|c|c|}
\hline & & CROBEX & BUX & SBITOP & BELEX15 \\
\hline $\mathrm{N}$ & & 252 & 252 & 252 & 252 \\
\hline \multirow[t]{2}{*}{ Normal Parameters ${ }^{2 b}$} & Mean & $2083,010 \mathrm{~s}$ & 20468.0758 & 724.8801 & 670.1108 \\
\hline & $\begin{array}{c}\text { Std. } \\
\text { Deviation }\end{array}$ & 200.92035 & 2879.32410 & 88.81687 & 103.59536 \\
\hline \multirow[t]{3}{*}{$\begin{array}{l}\text { Most Extreme } \\
\text { Differences }\end{array}$} & Absolute & 0.233 & 0.225 & 0.132 & 0.215 \\
\hline & Positive & 0.138 & 0.157 & 0.132 & 0.123 \\
\hline & Negative & -0.233 & -0.225 & -0.113 & -0.215 \\
\hline Kolmogorov-Smimov Z & & 3.693 & 3.565 & 2.093 & 3.410 \\
\hline Asymp. Sig. (2-tailed) & (p) & 0.000 & 0.000 & 0.000 & 0.000 \\
\hline
\end{tabular}

Based on the 2011 Kolmogorov-Smirnov test results, it can be concluded that the values of the observed indices are not normally distributed, i.e. there are significant differences between the sampling distribution and the normal distribution, as indicated by the values of (p) for CROBEX (0.000), BUX (0.000) SBITOP (0.000) and BELEX15 (0.000) (Table 6).

Based on the 2012 Kolmogorov-Smirnov test results, it can be concluded that the values of BUX, SBITOP and BELEX15 indices are not normally distributed, i.e. there are significant differences between the sampling distribution and the normal distribution, as indicated by the values of (p) for BUX (0.017), SBITOP (0.001) and BELEX15 (0.000). The values of CROBEX index are normally distributed (0.678) (Table 7). 
Table 7

Kolmogorov-Smirnov test of the normality of the distribution sample in 2012

\begin{tabular}{|l|c|r|r|r|r|}
\hline & & CROBEX & \multicolumn{1}{|c|}{ BUX } & \multicolumn{1}{c|}{ SBITOP } & \multicolumn{1}{|c|}{ BELEX15 } \\
\hline N & & 252 & 252 & 252 & 252 \\
\hline Normal Parameters & Mean & 1735.9712 & 18078.4705 & 566.7558 & 473.9669 \\
\hline & $\begin{array}{c}\text { Std. } \\
\text { Deviation }\end{array}$ & 55.11718 & 886.48560 & 34.73749 & 39.56733 \\
\hline $\begin{array}{l}\text { Most Extreme } \\
\text { Differences }\end{array}$ & Absolute & 0.045 & 0.098 & 0.125 & 0.174 \\
\hline & Positive & 0.045 & 0.062 & 0.121 & 0.174 \\
\hline & Negative & -0.036 & -0.098 & -0.125 & -0.121 \\
\hline Kolmogorov-Smimov Z & & 0.720 & 1.548 & 1.979 & 2.768 \\
\hline Asymp. Sig.(2-tailed) & (p) & 0.678 & 0.017 & 0.001 & 0.000 \\
\hline
\end{tabular}

Providing the above mentioned, based on the 2012 Kolmogorov-Smirnov test results, it can be concluded that the values of CROBEX, BUX, SBITOP and BELEX15 indices are different from a normal distribution in 2006, 2007, 2008 and 2011, while there is the normal distribution for the following index values: for CROBEX and BELEX15 in 2009, for BUX in 2010 and for CROBEX in 2012.

\section{Results and Discussion}

In this section, the hypotheses $\mathrm{H}_{1}, \mathrm{H}_{2}$ and $\mathrm{H}_{3}$ will be either proved or rejected for CROBEX, with the confidence level of $97.5 \%$, for 100 days, in the period from 2007 to 2012.

Table 8

The significance of the difference among the VaR calculation models in relation to performances of risk prediction for CROBEX (97.5\%; 100 days) in the period 2007-2012

\begin{tabular}{|r|r|r|r|}
\hline Analysis & $\mathrm{n}$ & $\mathrm{F}$ & $\mathrm{P}$ \\
\hline MANOVA & 6 & 4.088 & 0.000 \\
\hline Discriminant & 6 & 4.086 & 0.000 \\
\hline
\end{tabular}

Tables 8, 10, 12, 14, 16, 18, 20 and 22:

Legend: $n$-years (features), $F$ - the values of Fisher distribution, $p$ - significance level

Source: the author's calculations [11]

Based on the value of $\mathrm{p}=0.000$ (MANOVA analysis) and $\mathrm{p}=0.000$ (discriminant analysis), the hypotheses $\mathrm{H}_{1}$ and $\mathrm{H}_{2}$ are rejected; the alternative hypotheses $\mathrm{A}_{1}$ and $\mathrm{A}_{2}$ are accepted for CROBEX (97.5\%; 100 days). Consequently, there is the difference and the clearly defined boundary among VaR calculation models for CROBEX (97.5\%; 100 days). 
Table 9

The significance of the difference among the VaR calculation models in relation to performances of risk prediction for CROBEX $(97.5 \%$; 100 days $)$ in particular years

\begin{tabular}{|r|r|r|r|r|r|}
\hline Year & $\mathcal{Z}$ & $\mathrm{R}$ & $\mathrm{F}$ & $\mathrm{P}$ & d coeff \\
\hline 2009 & 0.087 & 0.087 & 2.884 & 0.057 & 0.020 \\
\hline 2005 & 0.020 & 0.020 & 0.150 & 0.861 & 0.009 \\
\hline 2009 & 0.023 & 0.023 & 0.201 & 0.818 & 0.000 \\
\hline 2010 & 0.100 & 0.100 & 3.813 & 0.023 & 0.020 \\
\hline 2011 & 0.062 & 0.062 & 1.476 & 0.230 & 0.023 \\
\hline 2012 & 0.026 & 0.026 & 0.255 & 0.775 & 0.009 \\
\hline
\end{tabular}

Tables 9, 11, 13, 15, 17, 19, 21 and 23:

Legend: $\chi$-Pearson's contingency coefficient, $R$-multiple correlation coefficient, $F$-Fischer value distribution, $p$ - significance level, $d$. coeff-discrimination coefficient Source: the author's calculations [11]

Since $\mathrm{p}<0.1$ (Roy 's test), the alternative hypothesis $\mathrm{A}_{3}$ is accepted, which means that there is a significant difference among the VaR calculation models for CROBEX (97.5\%; 100 days) in the performance of risk prediction, observed by years, such as: in 2007 (0.057) and in 2010 (0.023). Since p>0.1 (Roy's test), there is no reason not to accept the hypothesis $\mathrm{H}_{3}$, which means that no significant difference among the VaR calculation models for CROBEX is observed (97.5\%; 100 days) in the performances of risk prediction, by years, such as: in 2008 (0.861), in 2009 (0.818), in 2011 (0.230) and in 2012 (0.775). The discrimination coefficient indicates that the greatest contribution to discrimination, i.e. the biggest difference, is among the VaR calculation models for CROBEX (97.5\%; 100 days) in performances of risk prediction, in the following years, respectively: in 2011 (0.023) in 2007 (0.020), in 2010 (0.020), in 2008 (0.009) and in 2012 (0.009). It should be noted that the latent feature is the one in which there is no difference among the $\mathrm{VaR}$ calculation models, and discriminant analysis includes the same in the structure in which there is a significant difference among the VaR calculation models. The latent feature models are the years 2008 (0.861), 2011 (0.230) and $2012(0.775)$.

In this section, the hypotheses $\mathrm{H}_{1}, \mathrm{H}_{2}$ and $\mathrm{H}_{3}$ for CROBEX will be either proved or rejected, with a confidence level of $97.5 \%$, for 300 days, in the period from 2008 to 2012.

Table 10

The significance of the difference among the VaR calculation models in relation to performances of risk prediction for CROBEX (97.5\%; 300 days) in the period 2008-2012

\begin{tabular}{|r|r|r|r|}
\hline Analysis & $\mathrm{n}$ & $\mathrm{F}$ & $\mathrm{p}$ \\
\hline MANOVA & 5 & 0.007 & 1.000 \\
\hline Discriminant & 4 & 1.728 & 0.089 \\
\hline
\end{tabular}


Based on the values of $\mathrm{p}=1.000$ (MANOVA analysis) and $\mathrm{p}=0.089$ (discriminant analysis), there is no reason not to accept the hypothesis $\mathrm{H}_{1}$, reject the hypothesis $\mathrm{H}_{2}$ and accept the alternative hypothesis $\mathrm{A}_{2}$ for CROBEX (97.5\%; 300 days). This means that there is no difference among the VaR calculation models, but nevertheless, there is a clearly defined boundary among them. This fact suggests that there probably exist latent characteristics that in conjunction with other features (synthesized) contribute to discrimination of VaR calculation models. The starting unit, i.e. system, is reduced to the system of 4 features instead of 5 , with a difference and boundary existing among the VaR calculation models for CROBEX (97.5\%; 300 days).

Table 11

The significance of the difference among the VaR calculation models in relation to performances of risk prediction for CROBEX $(97.5 \%$; 300 days $)$ in particular years

\begin{tabular}{|r|r|r|r|r|r|}
\hline Year & $\gamma$ & R & F & P & d. coeff \\
\hline 2008 & 0.040 & 0.040 & 0.600 & 0.549 & 0.004 \\
\hline 2009 & 0.036 & 0.037 & 0.503 & 0.605 & 0.002 \\
\hline 2010 & 0.000 & 0.000 & 0.000 & 1.000 & 0.000 \\
\hline 2011 & 0.071 & 0.071 & 1.915 & 0.148 & 0.010 \\
\hline 2012 & 0.073 & 0.073 & 2.021 & 0.134 & 0.006 \\
\hline
\end{tabular}

Since $\mathrm{p}>0.1$ (Roy's test), there is no reason not to accept the hypothesis $\mathrm{H}_{3}$, which means that there is no significant difference among the VaR calculation models for CROBEX (97.5\%; 300 days) in the performances of risk prediction, in particular years, such as: in 2008 (0.549), in 2009 (0.605), in 2010 (1.000), in 2011 (0.148), and in 2012 (0.134). The discrimination coefficient indicates that the greatest contribution to discrimination, i.e. the most important difference, is among the VaR calculation models for CROBEX (97.5\%; 300 days) in performances of risk prediction, in the following years, respectively: in 2011 (0.010), in 2012 (0.006), in 2008 (0.004), and in 2009 (0.002). It should be noted that the latent feature is the one in which there is no difference among the VaR calculation models, and discriminant analysis includes the same in the structure in which there is a significant difference among the VaR calculation models. The latent feature models are the years 2008 (0.549), 2009 (0.605), $2011(0.148)$ and 2012 (0.134).

In this section, the hypotheses $\mathrm{H}_{1}, \mathrm{H}_{2}$ and $\mathrm{H}_{3}$ for BUX will be either proved or rejected, with a confidence level of $97.5 \%$ for 100 days, in the period from 2007 to 2012 . 
Table 12

The significance of the difference among the VaR calculation models in relation to performances of risk prediction for BUX (97.5\%; 100 days) in the period 2007-2012

\begin{tabular}{|r|r|r|r|}
\hline Analysis & $\mathrm{n}$ & $\mathrm{F}$ & $\mathrm{P}$ \\
\hline MANOVA & 6 & 3.135 & 0.000 \\
\hline Discriminant & 6 & 3.132 & 0.000 \\
\hline
\end{tabular}

Based on the values of $\mathrm{p}=0.000$ (MANOVA analysis) and $\mathrm{p}=0.000$ (discriminant analysis), the hypotheses $\mathrm{H}_{1}$ and $\mathrm{H}_{2}$ are rejected; the alternative hypotheses $\mathrm{A}_{1}$ and $\mathrm{A}_{2}$ are accepted for BUX $(97.5 \% ; 100$ days). Consequently, there is the difference and the clearly defined boundary among the VaR calculation models for BUX (97.5\%; 100 days).

Table 13

The significance of the difference among the VaR calculation models in relation to performances of risk prediction for BUX $(97.5 \%$; 100 days $)$ in particular years

\begin{tabular}{|r|r|r|r|r|r|}
\hline Year & $\chi$ & $\mathrm{R}$ & $\mathrm{F}$ & $\mathrm{p}$ & d. coeff \\
\hline 2007 & 0.080 & 0.081 & 2.462 & 0.086 & 0.013 \\
\hline 2008 & 0.034 & 0.034 & 0.441 & 0.644 & 0.008 \\
\hline 2009 & 0.078 & 0.078 & 2.315 & 0.100 & 0.008 \\
\hline 2010 & 0.056 & 0.056 & 1.171 & 0.311 & 0.014 \\
\hline 2011 & 0.040 & 0.040 & 0.619 & 0.539 & 0.024 \\
\hline 2012 & 0.030 & 0.030 & 0.337 & 0.714 & 0.003 \\
\hline
\end{tabular}

Since $p<0.1$ (Roy 's test), the alternative hypothesis $A_{3}$ is accepted, which means that there is a significant difference among some VaR calculation models for BUX ( $97.5 \%$; 100 days) in the performances of risk prediction, observed by years, such as in 2007 (0.086). Since p>0.1 (Roy's test), there is no reason not to accept the hypothesis $\mathrm{H}_{3}$, which means that no significant difference among the VaR calculation models for BUX is observed $(97.5 \%$; 100 days) in the performances of risk prediction, by years, such as: in 2008 (0.644), in 2009 (0.100), in 2010 $(0.311)$, in $2011(0.539)$ and in $2012(0.714)$. The discrimination coefficient indicates that the greatest contribution to discrimination, i.e. the biggest difference, is among the $\mathrm{VaR}$ calculation models for BUX (97.5\%; 100 days) in performances of risk prediction, in the following years, respectively: in 2011 (0.024), in 2010 (0.014), in 2007 (0.013), in 2008 (0.008), in 2009 (0.008) and in 2012 (0.003). It should be noted that the latent feature is the one in which there is no difference among the VaR calculation models, and discriminant analysis includes the same in the structure in which there is a significant difference among the VaR calculation models. The latent feature models are the years $2008(0.664)$, 2009 (0.100), 2010 (0.311), 2011 (0.539) and 2012 (0.714). 
In this section, the hypotheses $\mathrm{H}_{1}, \mathrm{H}_{2}$ and $\mathrm{H}_{3}$ for BUX will be either proved or rejected, with a confidence level of $97.5 \%$ for 300 days, in the period from 2008 to 2012 .

Table 14

The significance of the difference among the VaR calculation models in relation to performances of risk prediction for BUX (97.5\%; 300 days) in the period 2008-2012

\begin{tabular}{|r|r|r|r|}
\hline Analysis & $\mathrm{n}$ & $\mathrm{F}$ & $\mathrm{P}$ \\
\hline MANOVA & 5 & 2.537 & 0.005 \\
\hline Discriminant & 5 & 2.538 & 0.005 \\
\hline
\end{tabular}

Based on the value of $\mathrm{p}=0.005$ (MANOVA analysis) and $\mathrm{p}=0.005$ (discriminant analysis), the hypotheses $\mathrm{H}_{1}$ and $\mathrm{H}_{2}$ are rejected; the alternative hypotheses $\mathrm{A}_{1}$ and $\mathrm{A}_{2}$ are accepted for BUX $(97.5 \% ; 300$ days). Consequently, there is the difference and the clearly defined boundary among the VaR calculation models for BUX (97.5\%; 300 days).

Table 15

The significance of the difference among the VaR calculation models in relation to performances of risk prediction for BUX $(97.5 \%$; 300 days $)$ in particular years

\begin{tabular}{|r|r|r|r|r|r|}
\hline Year & $\chi$ & R & F & p & d. coeff \\
\hline 2008 & 0.007 & 0.007 & 0.017 & 0.983 & 0.003 \\
\hline 2009 & 0.066 & 0.066 & 1.645 & 0.194 & 0.018 \\
\hline 2010 & 0.048 & 0.048 & 0.884 & 0.414 & 0.002 \\
\hline 2011 & 0.074 & 0.074 & 2.077 & 0.126 & 0.012 \\
\hline 2012 & 0.073 & 0.073 & 2.011 & 0.135 & 0.010 \\
\hline
\end{tabular}

Since $\mathrm{p}>0.1$ (Roy's test), there is no reason not to accept the hypothesis $\mathrm{H}_{3}$, which means that there is no significant difference among the VaR calculation models for BUX (97.5\%; 300 days) in the performances of risk prediction, in particular years, such as: in 2008 (0.983), in 2009 (0.194), in 2010 (0.414), in 2011 (0.126) and in 2012 (0.135). The discrimination coefficient indicates that the greatest contribution to discrimination, i.e. the biggest difference, is among the VaR calculation models for BUX $(97.5 \%$; 300 days) in performances of risk prediction, in the following years, respectively: in 2009 (0.018), in 2011 (0.012), in 2012 (0.010), in $2008(0.003)$ and in $2010(0.002)$. It should be noted that the latent feature is the one in which there is no difference among the VaR calculation models, and discriminant analysis includes the same in the structure in which there is a significant difference among the VaR calculation models. The latent feature models are the years 2008 (0.983), 2009 (0.194), 2010 (0.414), $2011(0.126)$ and 2012 (0.135).

In this section, the hypotheses $\mathrm{H}_{1}, \mathrm{H}_{2}$ and $\mathrm{H}_{3}$ for SBITOP will be either proved or rejected, with a confidence level of $97.5 \%$, for 100 days, in the period from 2007 to 2012 . 
Table 16

The significance of the difference among the VaR calculation models in relation to performances of risk prediction for SBITOP $(97.5 \% ; 100$ days) in the period 2007-2012

\begin{tabular}{|r|r|r|r|}
\hline Analysis & $\mathrm{n}$ & $\mathrm{F}$ & $\mathrm{P}$ \\
\hline MANOVA & 6 & 2.336 & 0.006 \\
\hline Discriminant & 6 & 2.332 & 0.007 \\
\hline
\end{tabular}

Based on the value of $\mathrm{p}=0.006$ (MANOVA analysis) and $\mathrm{p}=0.007$ (discriminant analysis), the hypotheses $\mathrm{H}_{1}$ and $\mathrm{H}_{2}$ are rejected; the alternative hypotheses $\mathrm{A}_{1}$ and $\mathrm{A}_{2}$ are accepted for SBITOP $(97.5 \% ; 100$ days). Consequently, there is the difference and the clearly defined boundary among the VaR calculation models for SBITOP $(97.5 \% ; 100$ days).

Table 17

The significance of the difference among the VaR calculation models in relation to performances of risk prediction for SBITOP $(97.5 \%$; 100 days) in particular years

\begin{tabular}{|r|r|r|r|r|r|}
\hline Year & $\gamma$ & R & F & P & d. coeff \\
\hline 2007 & 0.096 & 0.096 & 3.509 & 0.031 & 0.017 \\
\hline 2008 & 0.025 & 0.025 & 0.239 & 0.788 & 0.002 \\
\hline 2009 & 0.036 & 0.037 & 0.503 & 0.605 & 0.000 \\
\hline 2010 & 0.052 & 0.052 & 1.026 & 0.359 & 0.006 \\
\hline 2011 & 0.043 & 0.043 & 0.704 & 0.495 & 0.007 \\
\hline 2012 & 0.056 & 0.056 & 1.196 & 0.303 & 0.013 \\
\hline
\end{tabular}

Since $\mathrm{p}<0.1$ (Roy's test), the alternative hypothesis $\mathrm{A}_{3}$ is accepted, which means that there is a significant difference among some $\mathrm{VaR}$ calculation models for SBITOP (97.5\%; 100 days) in the performances of risk prediction, observed by years, such as in 2007 (0.031). Since p>0.1 (Roy's test), there is no reason not to accept the hypothesis $\mathrm{H}_{3}$, which means that no significant difference among the $\mathrm{VaR}$ calculation models for SBITOP is observed (97.5\%; 100 days) in the performances of risk prediction, by years, such as: in 2008 (0.788), in 2009 (0.605), in 2010 (0.359), in 2011 (0.495) and in 2012 (0.303). The discrimination coefficient indicates that the greatest contribution to discrimination, i.e. the biggest difference, is among the VaR calculation models for SBITOP (97.5\%; 100 days) in the performance of risk prediction, in the following years, respectively: in 2007 (0.017), in $2012(0.013)$, in 2011 (0.007), in 2010 (0.006) and in 2008 (0.002). It should be noted that the latent feature is the one in which there is no difference among the $\mathrm{VaR}$ calculation models, and discriminant analysis includes the same in the structure in which there is a significant difference among the VaR calculation models. The latent feature models are the years 2008 (0.788), 2010 (0.359), 2011 (0.459) and 2012 (0.303). 
In this section, the hypotheses $\mathrm{H}_{1}, \mathrm{H}_{2}$ and $\mathrm{H}_{3}$ for SBITOP will be either proved or rejected, with a confidence level of $97.5 \%$ for 300 days, in the period from 2008 to 2012 .

Table 18

The significance of the difference among the VaR calculation models in relation to performances of risk prediction for SBITOP $(97.5 \% ; 300$ days) in the period 2008-2012

\begin{tabular}{|r|r|r|r|}
\hline Analysis & $\mathrm{n}$ & $\mathrm{F}$ & $\mathrm{P}$ \\
\hline MANOVA & 5 & 1.375 & 0.188 \\
\hline Discriminant & 2 & 2.022 & 0.090 \\
\hline
\end{tabular}

Based on the value of $\mathrm{p}=0.188$ (MANOVA analysis) and $\mathrm{p}=0.090$ (discriminant analysis), there is no reason not to accept the hypothesis $\mathrm{H}_{1}$ and reject the hypothesis $\mathrm{H}_{2}$, and accept the alternative hypothesis $\mathrm{A}_{2}$ for SBITOP $(97.5 \% ; 300$ days). It means that there is no significant difference among VaR calculation models, yet there exists a clearly defined boundary among the VaR calculation models. This fact indicates that probably there exist latent features that in conjunction with other features (synthesized) contribute to discrimination of VaR calculation models. The starting unit, i.e. system, is reduced to the system of 2 features instead of 5 , with a difference and boundary existing among VaR calculation models for SBITOP $(97.5 \% ; 300$ days $)$.

Table 19

The significance of the difference among the VaR calculation models in relation to performances of risk prediction for SBITOP $(97.5 \%$; 300 days $)$ in particular years

\begin{tabular}{|r|r|r|r|r|r|}
\hline Year & $\chi$ & $\mathrm{R}$ & $\mathrm{F}$ & $\mathrm{p}$ & d. coeff \\
\hline 2008 & 0.052 & 0.052 & 1.041 & 0.354 & 0.000 \\
\hline 2009 & 0.036 & 0.037 & 0.503 & 0.605 & 0.005 \\
\hline 2010 & 0.052 & 0.052 & 1.012 & 0.364 & 0.000 \\
\hline 2011 & 0.076 & 0.076 & 2.194 & 0.113 & 0.000 \\
\hline 2012 & 0.078 & 0.078 & 2.294 & 0.102 & 0.009 \\
\hline
\end{tabular}

Since $\mathrm{p}>0.1$ (Roy's test), there is no reason not to accept the hypothesis $\mathrm{H}_{3}$, which means that there is no significant difference among the VaR calculation models for SBITOP (97.5\%; 300 days) in the performances of risk prediction, in particular years, such as: in 2008 (0.354), in 2009 (0.605), in 2010 (0.364), in 2011 (0.113) and in 2012 (0.102). The discrimination coefficient indicates that the greatest contribution to discrimination, i.e. the biggest difference, is among $\mathrm{VaR}$ calculation models for SBITOP $(97.5 \%$; 300 days) in performances of risk prediction, in the following years, respectively: in 2012 (0.009) and in 2009 (0.005). It should be noted that the latent feature is the one in which there is no difference among the VaR calculation models, and discriminant analysis includes the same in the structure in which there is a significant difference among the VaR calculation models. The latent feature models are the years 2009 (0.605) and 2012 (0.102). 
In this section, the hypotheses $\mathrm{H}_{1}, \mathrm{H}_{2}$ and $\mathrm{H}_{3}$ for BELEX15 will be either proved or rejected, with a confidence level of $97.5 \%$, for 100 days, in the period from 2007 to 2012.

Table 20

The significance of the difference among the VaR calculation models in relation to performances of risk prediction for BELEX15 (97.5\%; 100 days) in the period 2007-2012

\begin{tabular}{|r|r|r|r|}
\hline Analysis & $\mathrm{n}$ & $\mathrm{F}$ & $\mathrm{p}$ \\
\hline MANOVA & 6 & 3.681 & 0.000 \\
\hline Discriminant & 6 & 3.688 & 0.000 \\
\hline
\end{tabular}

Based on the values of $\mathrm{p}=0.000$ (MANOVA analysis) and $\mathrm{p}=0.000$ (discriminant analysis), the hypotheses $\mathrm{H}_{1}$ and $\mathrm{H}_{2}$ are rejected; the alternative hypotheses $\mathrm{A}_{1}$ and $\mathrm{A}_{2}$ are accepted for BELEX15 (97.5\%; 100 days). Consequently, there is the difference and the clearly defined boundary among the VaR calculation models for BELEX15 (97.5\%; 100 days).

Table 21

The significance of the difference among the VaR calculation models in relation to performances of risk prediction for BELEX15 (97.5\%; 100 days) in particular years

\begin{tabular}{|r|r|r|r|r|r|}
\hline Year & $\chi$ & $\mathrm{R}$ & $\mathrm{F}$ & $\mathrm{p}$ & d. coeff \\
\hline 2007 & 0.039 & 0.039 & 0.567 & 0.568 & 0.024 \\
\hline 2008 & 0.027 & 0.027 & 0.266 & 0.766 & 0.013 \\
\hline 2009 & 0.030 & 0.030 & 0.337 & 0.714 & 0.002 \\
\hline 2010 & 0.068 & 0.069 & 1.782 & 0.169 & 0.012 \\
\hline 2011 & 0.037 & 0.037 & 0.517 & 0.597 & 0.020 \\
\hline 2012 & 0.091 & 0.091 & 3.160 & 0.043 & 0.016 \\
\hline
\end{tabular}

Since $\mathrm{p}<0.1$ (Roy's test), the alternative hypothesis $\mathrm{A}_{3}$ is accepted, which means that there is a significant difference among some $\mathrm{VaR}$ calculation models for BELEX15 (97.5\%; 100 days) in the performances of risk prediction, observed by years, such as in $2012(0.043)$. Since p>0.1 (Roy's test), there is no reason not to accept the hypothesis $\mathrm{H}_{3}$, which means that no significant difference among the VaR calculation models for BELEX15 is observed $(97.5 \% ; 100$ days) in the performances of risk prediction, by years, such as: in 2007 (0.568), in 2008 (0.766), in 2009 (0.714), in 2010 (0.169) and in 2011 (0.597). The discrimination coefficient indicates that the greatest contribution to discrimination, i.e. the biggest difference, is among the VaR calculation models for BELEX15 (97.5\%; 100 days) in the performances of risk prediction, in the following years, respectively: in 2007 (0.024), in 2011 (0.020), in 2012 (0.016), in 2008 (0.013), in $2010(0.012)$ and in 2009 (0.002). It should be noted that the latent feature is the one in which there is no difference among the VaR calculation models, and discriminant analysis includes the same in the structure in which there is a significant difference among the VaR calculation models. The latent feature models are the years 2007 (0.568), 2008 (0.766), 2009 (0.714), $2010(0.169)$ and 2011 (0.597). 
In this section, the hypotheses $\mathrm{H}_{1}, \mathrm{H}_{2}$ and $\mathrm{H}_{3}$ for BELEX15 will be either proved or rejected, with a confidence level of $97.5 \%$, for 300 days, in the period from 2008 to 2012.

Table 22

The significance of the difference among the VaR calculation models in relation to performances of risk prediction for BELEX15 (97.5\%; 300 days) in the period 2008-2012

\begin{tabular}{|r|r|r|r|}
\hline Analysis & $\mathrm{n}$ & $\mathrm{F}$ & $\mathrm{p}$ \\
\hline MANOVA & 5 & 1.001 & 0.442 \\
\hline Diseriminant & 2 & 1.465 & 0.212 \\
\hline
\end{tabular}

Based on the values of $\mathrm{p}=0.442$ (MANOVA analysis) and $\mathrm{p}=0.212$ (discriminant analysis), there is no reason not to accept the hypotheses $\mathrm{H}_{1}$ and $\mathrm{H}_{2}$. It means that there is no significant difference or a clearly defined boundary among the VaR calculation models. Not even after the reduction of the starting unit, i.e. system, from 5 to 2 features, there is no difference or boundary existing among the VaR calculation models for BELEX15 (97.5\%; 300 days).

Table 23

The significance of the difference among the VaR calculation models in relation to performances of risk prediction for BELEX15 (97.5\%; 300 days) in particular years

\begin{tabular}{|r|r|r|r|r|}
\hline Year & $\chi$ & $\mathrm{R}$ & $\mathrm{F}$ & $\mathrm{P}$ \\
\hline 2008 & 0.025 & 0.025 & 0.239 & 0.788 \\
\hline 2009 & 0.052 & 0.052 & 1.005 & 0.367 \\
\hline 2010 & 0.051 & 0.051 & 1.001 & 0.368 \\
\hline 2011 & 0.045 & 0.045 & 0.756 & 0.470 \\
\hline 2012 & 0.051 & 0.051 & 1.001 & 0.368 \\
\hline
\end{tabular}

Since $\mathrm{p}>0.1$ (Roy's test), there is no reason not to accept the hypothesis $\mathrm{H}_{3}$, which means that there is no significant difference among the VaR calculation models for BELEX15 (97.5\%; 300 days) in the performances of risk prediction, in particular years, such as: in 2008 (0.788), in 2009 (0.367), in $2010(0.368)$, in $2011(0.470)$ and in $2012(0.368)$.

\section{Conclusions}

When analyzing the results obtained in the research, it can be concluded that the tested risk management models used in investment risk prediction, enable the determination of the maximum possible loss from investment activities, in the observed markets. The results indicate that the rolling window, with fewer days, is more sensitive to changes in the daily index values. With the rolling window of 300 days, there are less mutual variations in effectiveness of the tested models.

Exploring the characteristics of the application of the models D VaR and EVT, based on the results obtained, it can be concluded that the differences in performance of these models are not significant, while with the HS VaR model 
these differences are much more considerable. Of course, practice confirms the exceptions, as well. In the case of the year 2011, the HS VaR and EVT models show greater similarity, so this fact can be a good basis for a subsequent study, which will be focused on even more analytical approach to the implementation of these models.

With the analysis of the research results, it can be concluded that the basic hypothesis $\mathrm{H}_{0}$ is rejected, i.e. there is a statistically significant difference among the Extreme Value Theory (EVT), Delta Normal VaR (D VaR) and Historical Simulation (HS VaR) models, according to successful investment risk prediction in the markets of the transition economies. The hypotheses $\mathrm{H}_{1}, \mathrm{H}_{2}$ and $\mathrm{H}_{3}$ are also rejected, which only confirms the need for the specific research in terms of testing implementation performances of the observed models in the analyzed markets.

Volatility of business, as a consequence of a global economic crisis, significantly affects the adequate implementation of the tested models of investment risk management, i.e. adequate predictions of the maximum possible losses from investing activities. Such conditions are characterized by extreme events ( extreme movements in the observed markets), low liquidity of the observed markets, low level of transparent business operations, their substantial inefficiency, incomplete institutional frameworks, and so on.

The importance of the research in this study has its academic, professional and practical dimensions. The academic dimension stems from the fact that until now very little research has been conducted in this area, focused on the markets of transition economies, so, in this respect, the conclusions obtained through the specific research open the "gate" for further steps in the analysis of the implementation of the tested risk management models for these markets. Professional-practical dimension of the research is the importance of the obtained information on the implementation specifics and modalities of the tested models in the observed transitional markets.

Considering all the above, further research will primarily focus on analysis of the specific implementations of the observed models in transitional markets, in terms of testing their adaptabilities, to the ever-changing conditions and turbulent environment, that is inherent in these markets. In this way, all the interested investment parties (academic and professional communities, policy makers, etc.) will have access to reliable information, that is, in practice, quantitatively tested concerning the possibilities of model implementation in transitional markets.

\section{Acknowledgement}

This work was supported by the Ministry of Education, Science and Technological Development of the Republic of Serbia, within the Project No. III47028. 


\section{References}

[1] G. Andjelic, V. Djakovic, Financial Market Co-Movement between Transition Economies: A Case Study of Serbia, Hungary, Croatia and Slovenia, Acta Polytechnica Hungarica, Journal of Applied Sciences, Budapest, Hungary, Vol. 9, No. 3, pp. 115-134, 2012

[2] G. B. Andjelic, V. Dj. Djakovic, M. M. Sujic, An Empirical Evaluation of Value-At-Risk: The Case of the Belgrade Stock Exchange Index BELEX15, Industrija, Vol. 40, No. 1, pp. 39-60, 2012

[3] J. Jockovic, Generalized Pareto Distributions in Extreme Value Theory and their Implementations, M.Sc. Thesis, University of Belgrade, Faculty of Mathematics, pp. 1-56, 2009

[4] J. V. Rosenberg, T. Schuermann, A General Approach to Integrated Risk Management with Skewed, Fat-tailed Risks, Staff Report, Federal Reserve Bank of New York, No. 185, pp. 1-59, 2004

[5] J. Y. Uppal, I. U. Mangla, Extreme Loss Risk in Financial TurbulenceEvidence from the Global Financial Crisis, Managerial Finance, Vol. 39, No. 7, pp. 653-666, 2013

[6] M. Ottenwaelter, Value-at-Risk for Commodity Portfolios, INP Grenoble ENSIMAG, pp. 1-43, 2008

[7] R. Campbell, R. Huisman, K. Koedijk, Optimal Portfolio Selection in a Value-at-Risk Framework, Journal of Banking and Finance, Vol. 25, No. 9, pp. 1789-1804, 2001

[8] S. Basak, A. Shapiro, Value-at-Risk-based Risk Management: Optimal Policies and Asset Prices, The Review of Financial Studies, Vol. 14, No. 2, pp. 371-405, 2001

[9] S. Zikovic, M. Pecaric, Modelling Extreme Events: Application to Zagreb Stock Exchange, Ekonomski pregled, Vol. 61, No. 1-2, pp. 19-37, 2010

[10] V. Bucevska, An Empirical Evaluation of GARCH Models in Value-atRisk Estimation: Evidence from the Macedonian Stock Exchange, Business Systems Research, Vol. 4, No. 1, pp. 49-64, 2013

[11] V. Djakovic, The Application of the Extreme Value Theory Model in Investments, Ph.D. Thesis, University of Novi Sad, Faculty of Technical Sciences, Novi Sad, Serbia, 227 p., 2013

[12] Y. Ait-Sahalia, A. W. Lo, Nonparametric Risk Management and Implied Risk Aversion, Journal of Econometrics, Vol. 94, No. 1-2, pp. 9-51, 2000 